\title{
Articles
}

\section{Relational Surprise Experiences as a Unique Form of Relational Maintenance}

\author{
Joshua R. Pedersonª, Leah E. LeFebvrea, Darrin J. Griffin ${ }^{a}$ \\ [a] Department of Communication Studies, University of Alabama, Tuscaloosa, AL, USA.
}

\begin{abstract}
This study presents an initial exploration and conceptualization of relational surprise experiences (RSEs) as communication phenomenon involving strategic relational maintenance behaviors with potential for positive and negative outcomes. University students in the Southeastern United States $(N=203)$ described a RSE that occurred with a close relational partner (romantic partner, friend, or family member), explained how deception was used to achieve the surprise, and reported relational benefits and drawbacks in an online survey. Seven types of RSEs were reported including gifts, events, visits, and destinations. Responses revealed that people considered surprises as relationally beneficial with minimal drawbacks. Although over one-third of the participants described their partner's pants perceived the surprise as a violation of relational rules. Some participants reported both benefits and drawbacks to RSEs, thereby illuminating a nuance for traditional relational maintenance typologies. This study establishes a path to explore implications of RSEs for individual and relational satisfaction, happiness, and well-being.
\end{abstract}

Keywords: surprise, deception, relational maintenance, close relationships, expectancy violation

Interpersona, 2020, Vol. 14(2), 118-136, https://doi.org/10.5964/ijpr.v14i2.3647

Received: 2020-04-30. Accepted: 2020-10-23. Published (VoR): 2020-12-22.

${ }^{*}$ Corresponding author at: Department of Communication Studies, University of Alabama, Box 870172, Tuscaloosa, AL, 35487, USA. E-mail: jrpederson@ua.edu

This is an open access article distributed under the terms of the Creative Commons Attribution 4.0 International License, CC BY 4.0 (https://creativecommons.org/licenses/by/4.0/), which permits unrestricted use, distribution, and reproduction in any medium, provided the original work is properly cited.

Close relational partners often enact strategic behaviors to maintain or grow relational closeness and intimacy (Canary \& Stafford, 1994) and these processes can impact individual well-being (e.g., Baker, McNulty, Overall, Lambert, \& Fincham, 2013). Over time relational partners develop expectations for what type of maintenance behaviors are welcomed, appreciated, and beneficial (Dainton, 2000). However, close relational partners often enact events or behaviors that may violate relational expectations and rules (Afifi \& Metts, 1998). For instance, relational partners often establish explicit or implicit relational rules of telling the truth or not hiding things from each other (Afifi, Caughlin, \& Afifi, 2007). However, prior research suggests that people deceive their partners to maintain or enhance their relationship (e.g., Cole, 2001; Horan \& Booth-Butterfield, 2013). Surprise experiences enacted by romantic partners, friends, and family members are an understudied phenomenon. A surprise from a relational partner might add excitement, create novelty, and increase closeness, but the behaviors used to enact the surprise might also violate relational rules, produce uncertainty, or raise questions about a partner's trust. These surprise experiences, then, likely carry implications for individual and relational satisfaction, happiness, and well-being. 
The current study explores relational surprise experiences (RSEs) as a unique form of relational maintenance behavior in which the planning, implementation, and outcomes of RSEs can be perceived as positive or negative, or both simultaneously. RSEs are strategically planned unexpected events occurring in close relationships intended for relational maintenance or enhancement. The purpose of this study is to explore the nature of RSEs, whether people perceive the behaviors used to carry out a RSE as deceptive and violations of relational rules, and to use relational maintenance research as a guiding framework to illuminate positive and negative outcomes of the RSEs. The goal of the current study is to lay the conceptual groundwork and provide initial understandings about RSEs.

\section{Surprises as Relational Maintenance}

Relationship maintenance refers to communicative behaviors that people say or do to keep their relationship in existence, in a specific state, or in a desired condition (Dindia \& Canary, 1993). Maintenance behaviors can occur in strategic or routine ways. Strategic behaviors are more mindfully intended to achieve a specific goal, whereas routine behaviors occurr in more habituated forms without concern for a particular goal (Canary \& Stafford, 1994). A well-established typology of relational maintenance behaviors includes positivity, openness, assurances, social networks, and sharing tasks (Stafford \& Canary, 1991) and prosocial behaviors, such as humor, constructive conflict, and supportiveness (Stafford, 2003). However, Dainton and Gross (2008) articulated several negative maintenance behaviors (e.g., destructive conflict, avoidance, jealousy induction) that can result in destructive consequences and even relationship termination. Minimal research exists on maintenance behaviors that are more ambiguous or that have the potential for simultaneous positive and negative relational outcomes. Such behaviors have potential to play a pivotal role in the trajectory of relational development. We propose RSEs as a form of relational maintenance that employs both positive and negative maintenance behaviors, which can result in relational benefits and drawbacks.

The term surprise can be conceptualized as an internal (i.e., emotion or cognitive state) or external (i.e., social experience) phenomenon. Commonly, surprise is defined as a basic emotion (Stets \& Turner, 2008). Although surprises possess physiological functions, they can also be understood as a cognitive state with valanced reactions (Ortony, Clore, \& Collins, 1988). Experiences that may follow surprise can be learned or contextualized in culture, and may be driven by individualized relational norms and expectations. Surprises might also function as a form of self-expansion that builds closeness and mitigates boredom in a relationship (Aron \& Aron, 1996), because they are a way to create novelty and excitement in a relationship (Malouff, Mundy, Galea, \& Bothma, 2015). Ultimately, a surprise is a reaction to an event that "exceeds some threshold value of unexpectedness" (Reisenzein, 2000, p. 264). For example, giving and receiving gifts could be unexpected surprises. In fact, giving gifts have been shown to improve self-reported and observed mood (Aknin, Fleerackers, \& Hamlin, 2014). Our investigation explores the communicative behaviors used to plan and enact the holistic RSE, and associated perceptions, evaluations, and outcomes of such interpersonal experiences.

\section{Deception in Close Relationships}

RSEs inherently involve degrees of deception. This study relies on Levine's (2014) definition to position RSEs as a deception- "intentionally, knowingly, and/or purposely misleading another person" (p. 379). Perceptions about intentionality play a role in evaluating the severity of deception. Surprise givers justify the concealing of information related to the surprise because it is for the benefit of the receiver and relationship. However, 
in relationships, discovering partners' use of lying and deception typically results in negative emotions and relational implications (McCornack \& Levine, 1990). People typically expect honesty in their partners and view deception as a cost to the relationship (Cole, 2001). Thus, deception in relationships (if discovered) may result in a violation of a relational rule.

Some deceptive behaviors are nonthreatening in that they merely serve to follow politeness rituals or are intended for relational maintenance (e.g., altruistic and self-serving social liesi; see Biziou-van-Pol, Haenen, Novaro, Occhipinti Liberman, \& Capraro, 2015; Erat \& Gneezy, 2012). These low stake forms of deception are socially acceptable forms of deception that generate little to no negative consequences for a receiver (Camden, Motley, \& Wilson, 1984). Some relational situations warrant using various forms of deception such as omission, half-truth, or withholding information. Research has demonstrated that relational partners often use low-stakes deception to express a position or feeling that does not represent how they feel (Camden et al., 1984). Specifically, a form of deception used in close relationships is deceptive affective messages (DAMs) that express affection inconsistent with senders' internal feelings (Horan \& Booth-Butterfield, 2011, 2013). For example, when people something that is different than what they are thinking or feeling. Research showed DAMs were not associated with relational commitment or satisfaction, rather greater frequency of general deception was associated with less commitment and satisfaction (Gillen \& Horan, 2013). Similarly, another study found that individuals perceiving high relational commitment were less likely to use DAMs (Redlick \& Vangelisti, 2018). Thus, RSEs are similar to altruistic social lies and DAMs, in that they are often intended to benefit the receiver or the relationship rather than using a deceptive strategy to hide feelings or information. RSEs can involve revealing information and deceptive strategies.

\section{RSEs as a Unique Form of Relational Maintenance}

There are two major distinctions between RSEs and other forms of relational maintenance including: 1) RSEs can involve normatively negative and positive behaviors in their enactment resulting in positive and/or negative perceptions and outcomes simultaneously or over time and 2) individuals planning RSEs eventually reveal much or all of their deception. First, behaviors, such as deception, used to plan and enact a surprise could be perceived as negative relational maintenance (Dainton \& Gross, 2008). But these deceptive behaviors might also be perceived positively because they were intended to promote novelty in the relationship (Guthrie \& Kunkel, 2013). The surprise event itself might be evaluated positively or negatively based on individual and relational preferences and expectations. Also, outcomes of the RSE can be positive, negative, or both, and change over time. In this way RSEs might function similarly to teasing in that seemingly negative content (e.g., hurtful message) or delivery (e.g., sarcasm) might be intended for play, humor, or affection to grow or maintain a relationship (Mills \& Babrow, 2003). However, RSEs are likely more of a strategic form of maintenance rather than more spontaneous teasing behaviors. RSEs also are more likely to involve deception and teasing is not.

Relational partners evaluate different forms of deception as more or less acceptable depending on the type of deception, context, relational history, and other factors (Gordon \& Miller, 2000). Judgments about the degree of positive implications for a relationship following deception can differ based on whether a person is enacting or receiving the deception (Kaplar \& Gordon, 2004). People are more supportive of enacting, rather than receiving, benevolent, or altruistic deception (Hart, Curtis, Williams, Hathaway, \& Griffith, 2014). Some forms of deception intended for benevolence can be less threatening to relational rules and satisfaction, but deception of any kind can violate idiosyncratic relational and general moral expectations (DePaulo \& Kashy, 1998). Thus, deception used to carry out RSEs can spark uncertainty, threaten a partner's trust, and represent morally repre- 
hensible behavior, while at the same time be intended to benefit the relationship. Although previous research has explored the motives (Guthrie \& Kunkel, 2013) and acceptability (Dunbar et al., 2016) of deception in close relationships, there have been no investigations into process and outcomes of RSEs as a form of relational maintenance.

The second distinction between RSEs and other forms of deception is that surprise givers plan to reveal some, if not all, of their motives and covert actions. Secrecy scholarship has alluded that secret keeping is part of enacting surprises, with minimal direct discussion of this phenomenon. Across multiple studies, surprises appeared infrequently as a type of secret kept from relational partners as compared to other secrets, such as sexual infidelity (Caughlin, Scott, Miller, \& Hefner, 2009). Keeping surprises are the least relational distancing and hurtful secret type (Caughlin et al., 2009). Findings suggest people might not consider behaviors used to enact surprises as deception. Secrets protect information individuals do not want their partners to find out, whereas a RSE is about hiding information that surprise givers eventually want to reveal to their partners (e.g., "I lied about having just a few people over"). Thus, we conceptualize the process and behaviors involved in RSEs as related, yet distinctly different from other forms of deception, secret keeping, and relational maintenance behaviors. Given minimal research on the types of RSEs and their potential to produce relationship benefits and drawbacks and the exploratory nature of this study we propose the following research questions:

$\mathrm{RQ1}$ : What types of surprises do people receive from their relational partners?

RQ2: How do people describe the relational benefits $(2 A)$ and drawbacks (2B) of surprises?

Conceptually, RSEs within close relationships complicate how relational partners evaluate relational maintenance behaviors. Partners often develop implicit and explicit relational rules to manage their relationships. They often value honesty and have rules against lying and manipulation (Roggensack \& Sillars, 2014) and carry the expectation that their partners will tell the truth. They emphasize openness and as such, favor revealing over concealing information (Afifi et al., 2007). Therefore, RSE violate the expectation of openness (Metts \& Cupach, 2007). Yet, we conceptualize RSEs as a form of relational maintenance that can enhance or maintain relational satisfaction, commitment, and closeness. Thus, the following research questions are posited to determine how RSEs alter relational maintenance perceptions and expectations:

RQ3: To what extent do people consider relational surprise experiences (RSEs) deceptive, and how severe, damaging, and harmful do they perceive this deception?

RQ4: How do people describe why (4A) or why not (4B) the RSE was deceptive?

RQ5: To what extent do people consider RSEs a violation of relational rules and how serious, intentional, and hurtful do they perceive the violation of rules?

RQ6: What are the differences, if any, between how givers and receivers of RSEs perceive deception, relational rule violations, benefits, and drawbacks related to RSEs? 


\section{Method}

\section{Participants}

Participants $(N=203)$ were recruited at a large Southeastern university in the United States. Average age of participants was 19.98 years $(S D=2.58)$ and ranged from 18 to 40 . The majority of participants identified as female $(73.9 \%)$, while the remainder of the sample identified as male $(24.1 \%)$, unidentified $(1.5 \%)$, and nonbinary (0.5\%). Participants mostly identified as European American (75.9\%), followed by African-American (7.4\%), Native American (5.9\%), Hispanic American (3.4\%), other (2.5\%, e.g., Italian or Hawaiian), Middle-Eastern American (2.0\%), and Asian American (1.5\%), and unidentified (1.5\%). The most common relationship for surprise experiences was romantic $(49.75 \%)$ followed by friend $(32.0 \%)$, parent $(11.8 \%)$, sibling $(4.9 \%)$, ex-romantic partner $(1.0 \%)$, and co-worker $(0.5 \%)^{\mathrm{ii}}$. On average, participants reported the surprises occurred about 8 months ago and ranged from 1 to 8 years $(M=213.13$ days, $S D=376.62, M d n=61$ days $)$.

\section{Procedures}

Participants volunteered by selecting the questionnaire hosted by Qualtrics from a database of research projects hosted by the college's research database for course participation or extra credit. The recruitment advertisement asked participants to recall a surprise experience involving a relational partner (e.g., romantic partner, friend, family member). After meeting requirements, participants read the Institutional Review Board informed consent page and clicked submit for agreement to begin the survey. Initially, participants were asked if they could recall a time when they gave or received a surprise to/from their relational partner. Thus, individuals participated as givers (37.9\%) and receivers $(62.1 \%)$ of RSEs. Surprise receivers were asked to describe the surprise experience in an open textbox by responding to the following prompt: "We are interested in exploring surprises in relationships. These surprises can be 'big' or 'small' surprises, but they should be surprises that were intended to be a positive experience. Describe the surprise experience. What happened?" The prompt elicited participants to provide as much detail as possible with no time or character limits. On average, participants' responses to the initial prompt averaged 15.61 words $(S D=10.62)$ and ranged from 2 to 53 words. Participants also described any relational benefits and drawbacks as a result of the surprise. Participants were asked if the surprise was deceptive and if the surprise violated any relational rules. Then participants completed several measurements including scales about perceptions of deceptiveness and rules violations as well as asked to describe why or why not the behaviors used to enact the surprise were deceptive (or not). Upon completion, students were offered either course participation or extra credit for their participation.

\section{Instrumentation}

\section{Deception}

To measure perceptions of deceptiveness (RQ3), we developed a forced dichotomous question with a yes or no response. The question asked, "Do you think your partner was deceptive with the surprise?" If participants indicated "yes" they responded to three questions using a 7-point Likert-type scale ( 1 = extremely low, $7=$ extremely high) about how severe, damaging, and harmful the deception was using the following stem "How was the deception?" 


\section{Rule Violations}

To measure perceptions about the surprise as rule violation (RQ5), participants responded to the question "Did your partner's behavior violate any relational rules?" by indicating "yes," "no," or "not sure." If participants answered "yes," then they were asked to rate, using an adapted 7-point Likert-type scale (Vangelisti \& Young, 2000), the violation seriousness, intentionality, and hurtfulness.

\section{Data Analysis}

In order to answer RQ1, RQ2, and RQ4, we performed a directed content analysis on the open-ended responses (Heish \& Shannon, 2005; Krippendorff, 2012). This approach derives the coding scheme from both previous scholarship and emergent categories that aid in building further description in a specific context. We analyzed the open-ended questions that corresponded with each separate research questions rather than reading across question promptsiii. In the first step, two authors read responses and created categories emerging from an iterative coding process. The unit of analysis was the entire participant response and only one code was assigned to each response (rather than allowing for multiple response). After initial categories were developed individually by identifying key concepts as initial coding criteria. Using this coding scheme, individual responses were reviewed again to determine categories determined similarities and differences to reduce confusion and increase mutual exclusive coding practices. A codebook was confirmed to describe newly formed categories. We coded the same randomly selected $10 \%$ of the sample for each open-ended question to establish reliability. Using Krippendorff's alpha, acceptable agreement between the coders was reached: RQ1 ( $\alpha=.71), \operatorname{RQ2A}(\alpha=.76), \operatorname{RQ2B}(\alpha=.82)$, RQ4A $(\alpha=1.00), \operatorname{RQ4B}(\alpha=.72)^{\mathrm{iv}}$. Differences were discussed with the remaining author as a form of analyst triangulation to make remaining adjustments to the category labels and offer further clarity for codes. Upon receiving reliability and difference dialogue, the remaining participant responses were divided and coded. Categories are conceptualized with definitions, exemplified by frequencies, and highlighted with exemplars.

\section{Results}

\section{RQ1-Types of Surprises}

Surprise receivers $(n=126)$ provided the types of surprises they received from relational partners. Seven categories emerged: tangible gifts, event-driven, visit, destination, miscellaneous, correspondences, and emotions (see Table 1 for frequencies, definitions, and exemplars). The most frequent surprise received was a tangible gift (34.9\%), whereby participants reported receiving a gift for special occasions, after achieving goals, or for no particular reason. These gifts were unexpected for the specific moment/context, or unexpected for their relationship. The next most frequent category was event-driven (29.4\%). These surprises involved relational partners performing something special for a recognized holiday or relational occasion. Next, visit surprises $(14.3 \%)$ involved unexpected, yet welcomed, opportunities to see people they cared about. Visit surprises gave participants a chance to spend quality time with a loved one they otherwise would not have had. Destination surprises (11.1\%) involved relational partners traveling to special location or experience. Traveling for a surprise offered relational partners a novel way to make memories and build relational intimacy. The remaining categories were miscellaneous (6.3\%), correspondence $(2.4 \%)$, and emotions $(1.6 \%)$. 
Table 1

Types of Surprises

\begin{tabular}{|c|c|c|c|c|}
\hline Category & $n$ & $\%$ & Definition & Example \\
\hline Tangible gift & 44 & 34.9 & $\begin{array}{l}\text { Physical signifier of } \\
\text { importance of relationship }\end{array}$ & $\begin{array}{l}\text { "She went on vacation with her family and knows I collect shot glasses } \\
\text { and brought one back for me." }\end{array}$ \\
\hline Event-driven & 37 & 29.4 & $\begin{array}{l}\text { Recognized holiday or } \\
\text { relational occasion }\end{array}$ & $\begin{array}{l}\text { "It was for my birthday last year I wasn't expecting anything big but he } \\
\text { planned an entire scavenger hunt and presents." }\end{array}$ \\
\hline Visit & 18 & 14.3 & $\begin{array}{l}\text { Surprise giver came to see } \\
\text { the person }\end{array}$ & $\begin{array}{l}\text { "My girlfriend doesn't actually live in [city], she usually comes down for } \\
\text { the weekends. But she showed up in the middle of the week without } \\
\text { letting me know." }\end{array}$ \\
\hline Location & 14 & 11.1 & $\begin{array}{l}\text { Surprise giver took recipient } \\
\text { to a location or event }\end{array}$ & $\begin{array}{l}\text { "I told him I wanted to go see an elephant at the zoo, and the other day } \\
\text { he just picked me up and drove to the zoo." }\end{array}$ \\
\hline Miscellaneous & 8 & 6.3 & $\begin{array}{l}\text { Nonsensical or } \\
\text { unrecognizable }\end{array}$ & - \\
\hline Correspondences & 3 & 2.4 & $\begin{array}{l}\text { Received unexpected } \\
\text { message }\end{array}$ & $\begin{array}{l}\text { "Got a surprise postcard in the mail from my parents while they were in } \\
\text { Europe." }\end{array}$ \\
\hline Emotions & 2 & 1.6 & $\begin{array}{l}\text { Unknown or unbidden } \\
\text { feelings expressed }\end{array}$ & $\begin{array}{l}\text { "Out of nowhere this person admitted to having feelings for me when } \\
\text { we had multiple times agreed on just being friends." }\end{array}$ \\
\hline
\end{tabular}

\section{RQ2A-Relational Benefits of Surprises}

Participants described surprises benefiting their relationship (see Table 2 for frequencies, definitions, and exemplars). The most frequent benefit, closeness (39.5\%), operated as a catalyst for growing their relationship and strengthening commitment. Overall, this category showed that surprises could be a positive behavior for relational maintenance or enhancement. The second most frequent relational benefit, positive feelings (27.6\%) influenced individual's affective state or emotional experience. This category suggested the surprise events made people feel better. The next category represented no benefits $(14.6 \%)$ with individuals not perceiving any benefits from the surprise experience. The remaining types of surprise benefits were categorized as memorable moments $(11.9 \%)$, tangible $(4.3 \%)$, and miscellaneous $(2.2 \%)$.

Table 2

Relational Benefits of Surprises

\begin{tabular}{|c|c|c|c|c|c|c|c|c|}
\hline \multirow[b]{2}{*}{ Category } & \multicolumn{2}{|c|}{ Total } & \multicolumn{2}{|c|}{ Received } & \multicolumn{2}{|c|}{ Gave } & \multirow[b]{2}{*}{ Definition } & \multirow[b]{2}{*}{ Example } \\
\hline & $n$ & $\%$ & $n$ & $\%$ & $n$ & $\%$ & & \\
\hline Closeness & 73 & 39.5 & 52 & 44.4 & 21 & 30.9 & $\begin{array}{l}\text { Strengthened bond between } \\
\text { partners }\end{array}$ & $\begin{array}{l}\text { "Our relationship grew stronger, we had the } \\
\text { opportunity to define our relationship goals } \\
\text { more deeply, and make more plans to see } \\
\text { each other." }\end{array}$ \\
\hline
\end{tabular}




\begin{tabular}{|c|c|c|c|c|c|c|c|c|}
\hline \multirow[b]{2}{*}{ Category } & \multicolumn{2}{|c|}{ Total } & \multicolumn{2}{|c|}{ Received } & \multicolumn{2}{|c|}{ Gave } & \multirow[b]{2}{*}{ Definition } & \multirow[b]{2}{*}{ Example } \\
\hline & $n$ & $\%$ & $n$ & $\%$ & $n$ & $\%$ & & \\
\hline Positive feelings $^{a}$ & 51 & 27.6 & 22 & 18.8 & 29 & 42.6 & $\begin{array}{l}\text { Created positive moods or } \\
\text { emotions }\end{array}$ & $\begin{array}{l}\text { "The only benefit of the surprise was the } \\
\text { joy of seeing my best friend's face light up } \\
\text { with complete, overwhelming happiness } \\
\text { and disbelief." }\end{array}$ \\
\hline None & 27 & 14.6 & 21 & 17.9 & 6 & 8.8 & There was no benefit & "No benefits." \\
\hline $\begin{array}{l}\text { Memorable } \\
\text { moments }\end{array}$ & 22 & 11.9 & 13 & 11.1 & 9 & 13.2 & $\begin{array}{l}\text { Experience created a } \\
\text { milestone in relationship }\end{array}$ & $\begin{array}{l}\text { "We became a lot closer throughout the } \\
\text { course of the festival. No longer did my } \\
\text { experiences at these events only exist in } \\
\text { my re-telling but we now had this } \\
\text { experience together. I was able to show } \\
\text { him a whole new world." }\end{array}$ \\
\hline Tangible & 8 & 4.3 & 6 & 5.1 & 2 & 2.9 & Physical or monetary gift & $\begin{array}{l}\text { "She was very happy and made me dinner } \\
\text { and treated me at the end of the night." }\end{array}$ \\
\hline Miscellaneous & 4 & 2.2 & 3 & 2.6 & 1 & 1.5 & $\begin{array}{l}\text { Nonsensical or } \\
\text { unrecognizable }\end{array}$ & - \\
\hline
\end{tabular}

Note. $N=185$.

aDenotes statistically significant difference between groups.

\section{RQ2B-Relational Drawbacks to Surprises}

Participants responded about their relational drawbacks related to giving or receiving surprises (see Table 3 for frequencies, definitions, and exemplars). The overwhelming majority reported experiencing no relational drawbacks or negatives as a result of the surprise experience, categorized as none $(71.4 \%)$. However, several participants expressed drawbacks. The next most common category, shifted expectations (6.5\%), reflected futuristic expectations. The next drawback category focused on negative feelings (4.3\%). Remaining drawback categories included miscellaneous (4.3\%), deceptive (3.8\%), disconnect (3.8\%), out of control (3.2\%), and highlights absence (2.7\%).

Table 3

Relational Drawbacks of Surprises

\begin{tabular}{|c|c|c|c|c|c|c|c|c|}
\hline \multirow[b]{2}{*}{ Category } & \multicolumn{2}{|c|}{ Total } & \multicolumn{2}{|c|}{ Received } & \multicolumn{2}{|c|}{ Gave } & \multirow[b]{2}{*}{ Definition } & \multirow[b]{2}{*}{ Example } \\
\hline & $n$ & $\%$ & $n$ & $\%$ & $n$ & $\%$ & & \\
\hline None & 132 & 71.4 & 81 & 70.4 & 51 & 72.9 & There were no drawbacks & $\begin{array}{l}\text { "There were no negatives, only positive } \\
\text { things came out of the surprise party." }\end{array}$ \\
\hline Shifted expectations & 12 & 6.5 & 8 & 7.0 & 4 & 5.7 & $\begin{array}{l}\text { Altered expectations or created } \\
\text { unanticipated outcomes }\end{array}$ & $\begin{array}{l}\text { "You expect those same acts to happen } \\
\text { again but reality hits and it doesn't } \\
\text { happen later in the relationship as much } \\
\text { as it did in the beginning." }\end{array}$ \\
\hline Negative feelings & 8 & 4.3 & 5 & 4.3 & 3 & 4.3 & $\begin{array}{l}\text { Created negative moods or } \\
\text { emotions }\end{array}$ & $\begin{array}{l}\text { "He can and has held it against me for } \\
\text { some things and can take it back even } \\
\text { though it is mine." }\end{array}$ \\
\hline
\end{tabular}




\begin{tabular}{|c|c|c|c|c|c|c|c|c|}
\hline \multirow[b]{2}{*}{ Category } & \multicolumn{2}{|c|}{ Total } & \multicolumn{2}{|c|}{ Received } & \multicolumn{2}{|c|}{ Gave } & \multirow[b]{2}{*}{ Definition } & \multirow[b]{2}{*}{ Example } \\
\hline & $n$ & $\%$ & $n$ & $\%$ & $n$ & $\%$ & & \\
\hline Miscellaneous & 8 & 4.3 & 7 & 6.1 & 1 & 1.4 & Nonsensical or unrecognizable & - \\
\hline Deceptive & 7 & 3.8 & 1 & 0.9 & 6 & 8.6 & $\begin{array}{l}\text { Awareness of potential } \\
\text { deceptiveness in the } \\
\text { relationship }\end{array}$ & $\begin{array}{l}\text { "He may have felt that I had broken the } \\
\text { trust between us by lying." }\end{array}$ \\
\hline Disconnect & 7 & 3.8 & 5 & 4.3 & 2 & 2.9 & $\begin{array}{l}\text { Incompatibility or mismatched } \\
\text { relationship perspective } \\
\text { between partners }\end{array}$ & $\begin{array}{l}\text { "It complicated our overall relationship } \\
\text { and many questions were left } \\
\text { unanswered." }\end{array}$ \\
\hline Out-of-control & 6 & 3.2 & 4 & 3.5 & 2 & 2.9 & $\begin{array}{l}\text { Uncomfortableness associated } \\
\text { with lack of control of situations }\end{array}$ & $\begin{array}{l}\text { "I don't LOVE surprises, I like to plan for } \\
\text { things usually." }\end{array}$ \\
\hline Highlights absence & 5 & 2.7 & 4 & 3.5 & 1 & 1.4 & $\begin{array}{l}\text { Longing for continued } \\
\text { interaction or togetherness }\end{array}$ & $\begin{array}{l}\text { "Seeing him makes me miss him, so I } \\
\text { guess one negative would be that after } \\
\text { he left I was a little bummed out for a } \\
\text { day or so." }\end{array}$ \\
\hline
\end{tabular}

Note. $N=185$.

Participants that reported both benefits and drawbacks highlighted the unique relational maintenance properties of RSEs. Of the 158 participants that reported a benefit, $41(25.9 \%)$ also reported at least one drawback. Thus, one fourth of the participants essentially reported paradoxical accounts (i.e., both positive and negative evaluations) of the RSEs outcomes. No discernable patterns in the types of benefits that paired with drawbacks were observed. Also, $12.4 \%$ participants did not report either benefit or drawback. In total, $34.6 \%$ of the sample evidenced paradoxical, dynamic, or uncertain evaluations of RSEs.

\section{RQ3 and RQ4-RSEs as Deception}

To provide understanding about whether people perceived relational partners to be deceptive when enacting surprise experiences, participants were asked, "Do you think you (your partner) was deceptive with the surprise?" Approximately one third (36.9\%) of the participants answered yes indicating that they thought deception was involved (see Table 4). Those participants answering yes rated deception as not particularly severe $(M=$ $2.59, S D=1.89)$, minimally damaging $(M=1.56, S D=1.35)$, and only slightly harmful $(M=1.64, S D=1.48)$. Overall, results showed that people perceived either no deception occurring in RSEs or that it was minimally severe and damaging .

Table 4

Differences Between Received and Given Surprise Experiences

\begin{tabular}{|c|c|c|c|c|c|c|c|c|c|}
\hline \multirow[b]{2}{*}{ Variable } & \multicolumn{3}{|c|}{ Total $(n=201)$} & \multicolumn{3}{|c|}{ Received $(n=125)^{\mathrm{a}}$} & \multicolumn{3}{|c|}{ Gave $(n=76)^{a}$} \\
\hline & Yes & No & Not sure & Yes & No & Not sure & Yes & No & Not sure \\
\hline Partner (or I) was deceptive? & 75 & 126 & & 40 & 85 & & 35 & 41 & \\
\hline Surprise violated relational rules? & 3 & 183 & 15 & 2 & 117 & 6 & 1 & 66 & 9 \\
\hline
\end{tabular}

Both groups had one missing case for the above items. 
Participants then explained why they thought their RSEs were deceptive (see Table 5). Lying (27.4\%) was the most common description. Responses described how surprise givers created false information, and knowingly deceived through acts of commission. The next most frequent reason, information deficit (21.9\%), suggested surprise receivers were not privy to the planning. The next most frequent reason, withholding (20.5\%), indicated that their partners discussed related surprise information, but givers intentionally withheld important information. The remaining categories were miscellaneous (17.8\%), necessity (8.3\%), and trickery $(4.1 \%)$.

Table 5

Reasons Surprise Were Perceived as Deceptive

\begin{tabular}{|c|c|c|c|c|c|c|c|c|}
\hline \multirow[b]{2}{*}{ Category } & \multicolumn{2}{|c|}{ Total } & \multicolumn{2}{|c|}{ Received } & \multicolumn{2}{|c|}{ Gave } & \multirow[t]{2}{*}{ Definition } & \multirow[t]{2}{*}{ Example } \\
\hline & $n$ & $\%$ & $n$ & $\%$ & $n$ & $\%$ & & \\
\hline Lying & 20 & 27.4 & 7 & 18.4 & 13 & 37.1 & $\begin{array}{l}\text { Giver intentionally created } \\
\text { or gave false information } \\
\text { (deception by } \\
\text { commission) }\end{array}$ & $\begin{array}{l}\text { "Because I had asked a few times about his } \\
\text { weekend plans and he had lied, but while it } \\
\text { was a lie to do something good for me, a lie is } \\
\text { a lie, so it was still deceptive." }\end{array}$ \\
\hline Information deficit & 16 & 21.9 & 9 & 23.6 & 7 & 20.0 & $\begin{array}{l}\text { Recipient lacked } \\
\text { knowledge of the } \\
\text { circumstance }\end{array}$ & $\begin{array}{l}\text { "I had no idea he had a week off, and he } \\
\text { never mentioned anything about it." }\end{array}$ \\
\hline Withholding & 15 & 20.5 & 8 & 21.1 & 7 & 20.0 & $\begin{array}{l}\text { Receiver had some } \\
\text { knowledge but giver } \\
\text { omitted crucial information } \\
\text { about surprise (deception } \\
\text { by omission) }\end{array}$ & "He hid it from me and kept it secret." \\
\hline Miscellaneous & 13 & 17.8 & 9 & 23.6 & 4 & 11.4 & $\begin{array}{l}\text { Nonsensical or } \\
\text { unrecognizable }\end{array}$ & $\begin{array}{l}\text { Participants did not respond to the question or } \\
\text { responded with statements such as "just } \\
\text { was." }\end{array}$ \\
\hline Behavioral control & 6 & 8.3 & 4 & 10.5 & 2 & 5.7 & $\begin{array}{l}\text { Manipulate access to } \\
\text { information }\end{array}$ & $\begin{array}{l}\text { "He never does that anymore and he did it to } \\
\text { cover the mean side to him. It really made me } \\
\text { think that he was perfect and thought that he } \\
\text { would do it more often but that was the first } \\
\text { and last time he ever surprised me." }\end{array}$ \\
\hline Trickery & 3 & 4.1 & 1 & 2.6 & 2 & 5.7 & $\begin{array}{l}\text { False impression or } \\
\text { inference dodge }\end{array}$ & $\begin{array}{l}\text { "I did not act suspicious about anything. I } \\
\text { talked about doing something completely } \\
\text { different for her birthday, so she would have } \\
\text { no idea. I did not really tell anyone either, just } \\
\text { in case someone could have let it slip." }\end{array}$ \\
\hline
\end{tabular}

Note. $N=73$.

Participants who indicated surprises were not deceptive also described their reasons (see Table 6). The most frequent reason implied not perceived as deceptive (27.3\%). This reason conveyed surprise receivers did not perceive that givers used explicit or noticeable deceptive behaviors to enact surprises, even if those behaviors fit a scholarly definition of deception. To these participants behaviors used to carry out the RSE were not perceived as deceptive because they did not meet the participants' criteria for what is considered deceptive. The next reason, positive intentions (22.3\%), suggested participants did not perceive behaviors used in RSEs 
to be deceptive because RSEs givers were benevolent. Other categories about why the surprise was not deceptive included event driven (20.7\%), miscellaneous (13.2\%), trait (9.1\%), do not know (4.1\%), relational benefit $(1.7 \%)$, and redemption (1.7\%).

Table 6

Reasons Surprises Were Not Perceived as Deceptive

\begin{tabular}{|c|c|c|c|c|c|c|c|c|}
\hline \multirow[b]{2}{*}{ Category } & \multicolumn{2}{|c|}{ Total } & \multicolumn{2}{|c|}{ Received } & \multicolumn{2}{|c|}{ Gave } & \multirow[b]{2}{*}{ Definition } & \multirow[b]{2}{*}{ Example } \\
\hline & $n$ & $\%$ & $n$ & $\%$ & $n$ & $\%$ & & \\
\hline $\begin{array}{l}\text { Not perceived as } \\
\text { deception }\end{array}$ & 33 & 27.3 & 22 & 26.5 & 11 & 28.9 & $\begin{array}{l}\text { Did not perceive explicit } \\
\text { falsehood or deceptive } \\
\text { maneuver, circumstantial }\end{array}$ & $\begin{array}{l}\text { "She wasn't lying to me about it and we never } \\
\text { talked about it." }\end{array}$ \\
\hline Positive intentions & 27 & 22.3 & 23 & 27.7 & 4 & 10.5 & $\begin{array}{l}\text { Perceived recipient } \\
\text { happiness or positivity as } \\
\text { an outcome for the } \\
\text { recipient }\end{array}$ & $\begin{array}{l}\text { "It was an act done with good heart, she } \\
\text { wasn't hiding anything from me." }\end{array}$ \\
\hline Event driven & 25 & 20.7 & 13 & 15.7 & 12 & 31.6 & $\begin{array}{l}\text { Inherent rules around the } \\
\text { normative occasion or } \\
\text { holiday }\end{array}$ & "Getting flowers isn't sneaky." \\
\hline Miscellaneous & 16 & 13.2 & 8 & 9.6 & 8 & 21.1 & $\begin{array}{l}\text { Nonsensical or } \\
\text { unrecognizable }\end{array}$ & $\begin{array}{l}\text { Participants did not respond to the question or } \\
\text { responded with statements such as "It was } \\
\text { just pizza." }\end{array}$ \\
\hline Trait & 11 & 9.1 & 9 & 10.8 & 2 & 5.3 & $\begin{array}{l}\text { Stable personal } \\
\text { characteristic of integrity } \\
\text { superseded act }\end{array}$ & $\begin{array}{l}\text { "He is an honest man and I believe in my } \\
\text { heart that he would never do anything } \\
\text { deceptive towards me. Everything he does, } \\
\text { he does to ultimately benefit our future." }\end{array}$ \\
\hline Do not know & 5 & 4.1 & 4 & 4.8 & 1 & 2.6 & $\begin{array}{l}\text { Lack of outcome, and } \\
\text { consequently outside their } \\
\text { perception of deception }\end{array}$ & $\begin{array}{l}\text { "Idk it just wasn't really a big deal, I thought it } \\
\text { was cool." }\end{array}$ \\
\hline Relational benefit & 2 & 1.7 & 2 & 2.4 & 0 & 0.0 & $\begin{array}{l}\text { Perceived recipient } \\
\text { happiness or positivity as } \\
\text { an outcome for the } \\
\text { relationship }\end{array}$ & "Because it benefited us." \\
\hline Redemption & 2 & 1.7 & 2 & 2.4 & 0 & 0.0 & $\begin{array}{l}\text { Act of regaining } \\
\text { relationship standing }\end{array}$ & $\begin{array}{l}\text { "My friend was just being nice and trying to } \\
\text { make up for her mistake." }\end{array}$ \\
\hline
\end{tabular}

Note. $N=121$.

\section{RQ5-Surprises as Violations of Relational Rules}

The overwhelming majority of participants reported their surprise experience did not violate any relational rules $(90.1 \%)$ regardless of whether they were receiving $(92.9 \%)$ or giving (85.7\%) the surprise (see Table 4). However, some participants $(7.4 \%)$ were not sure if the surprise violated relational rules. Results showed that whether people perceived their relational partners to be deceptive or not, surprise experiences were perceived as acceptable relational experiences that did not violate relational rules. 


\section{RQ6-Giving versus Receiving Surprises}

The last $R Q$ explored the differences between surprise givers and receivers. Using chi-square tests, the frequencies were compared for responses about benefits, drawbacks, and surprise was deception. Chi-square tests revealed no differences between givers and receivers for drawbacks and why the surprise was (not) deceptive. But there was a statistically significant difference for types of benefits: $X^{2}(5, N=185)=14.20$, $p=.014$. A post-hoc $z$-test using a Bonferroni correction revealed a significant difference with the category of positive feelings in that surprise givers reported more of this type of benefit than people who received a surprise.

To determine perception differences between givers and receivers, independent samples $t$-test for variables associated with deceptiveness (severity, damaging, and harmful) was conducted. Results found no statistically significant differences in deception perceptions between givers and receivers (see Table 7 for means and standard deviations) $)^{\mathrm{vi}}$. People perceived minimal consequences to RSEs, regardless of whether they were giving or receiving the surprise.

Table 7

Differences Between Received and Given Surprise Experiences

\begin{tabular}{|c|c|c|c|c|c|c|c|c|c|c|c|}
\hline \multirow[b]{2}{*}{ Variable } & \multicolumn{3}{|c|}{ Total } & \multicolumn{3}{|c|}{ Received } & \multicolumn{3}{|c|}{ Gave } & \multicolumn{2}{|c|}{$t$-test } \\
\hline & $n$ & $M$ & $S D$ & $n$ & $M$ & $S D$ & $n$ & $M$ & $S D$ & $t$ & $p$ \\
\hline \multicolumn{12}{|l|}{ Deception } \\
\hline Severity & 75 & 2.59 & 1.89 & 40 & 2.73 & 1.99 & 35 & 2.43 & 1.79 & 0.68 & .50 \\
\hline Damaging & 75 & 1.56 & 1.35 & 40 & 1.63 & 1.39 & 35 & 1.49 & 1.31 & 0.44 & .66 \\
\hline Harmful & 75 & 1.64 & 1.48 & 40 & 1.63 & 1.37 & 35 & 1.66 & 1.61 & -0.09 & .93 \\
\hline \multicolumn{12}{|c|}{ Rules violation } \\
\hline Serious & 3 & 5.00 & 3.46 & 2 & 4.00 & 4.24 & 1 & 7.00 & & & \\
\hline Intentional & 3 & 5.33 & 2.89 & 2 & 4.50 & 3.54 & 1 & 7.00 & & & \\
\hline Hurtful & 3 & 5.00 & 3.46 & 2 & 4.00 & 4.24 & 1 & 7.00 & & & \\
\hline
\end{tabular}

\section{Discussion}

This study explored the nature, evaluations, and outcomes of RSEs. A typology of relational surprises was developed that articulates relational benefits and drawbacks of RSEs. Most participants reported relational benefits following the RSE and most did not perceive the behaviors enacted to carry out the RSE as deceptive. However, of the participants that reported a benefit, about $26 \%$ of those people also reported at least one drawback. Additionally, one-third of the sample perceived the behaviors used in the RSE to be deceptive, albeit a non-threatening form of deception. Thus, participants did not perceive deception used in RSEs to violate expectations in relational rules.

As one of the first investigations of RSEs, findings suggest people frequently enacted surprises to give gifts, celebrate special occasions, make surprise appearances, and take relational partners on trips. Establishing a typology is important for understanding a potentially common, yet complex, form of relational maintenance. The RSE typology showcases strategic behaviors that can blur the line between positive and negative relational maintenance. RSEs allow relational partners to employ deceptive behaviors, which could be evaluated nega- 
tively, to maintain relationships by manifesting novelty. Additionally, this typology adds nuance to previous typologies of relational maintenance (Stafford \& Canary, 1991), by demonstrating how RSEs prioritize actions over verbal communication (e.g., openness, positivity, or assurances).

Some participants (36.9\%) perceived their partner (or themselves) to be deceptive when carrying out surprises. However, deception used in RSEs was rated as minimally severe and few considered them violating any relational rules. Participants perceived their RSEs to be relationally beneficial since they brought partners closer together, increased positive emotions, and created memorable moments. Nonetheless, RSEs were not universally positive for relationships. Several noted their relational expectations changed after the surprise or that they had to reciprocate in some way in the future. RSEs might serve as a barometer of relational development as partners negotiate rules and expectations surrounding the appropriateness of relational maintaining or enhancing behaviors.

Finally, no statistically significant differences emerged in terms of the deception perceptions used in RSEs between givers and receivers. Potentially givers may have felt justified in their use of deception because the surprise would benefit their partner and relationship. Receivers might have evaluated the deception based on the RSE outcomes. If the RSE was a positive experience and increased or maintained one's affection for their partner, then the deception was not labeled as deception or was not salient or relationally meaningful. Even so, there could have been uncertainty about how a partner was able to plan the surprise without detection. Some participants began to question their mutual trust based on the deception used to enact the surprise. Experiencing conflicting or dynamic evaluations of the planning, event, and outcomes of RSEs sets up a potential relational maintenance paradox and brings about theoretical insights.

\section{Theoretical Connections}

These findings open up questions for theorizing and conceptualizing the processes of expectations and maintenance in close relationships. First, further understanding of the process of RSEs starts to problematize how expectancy violations occur in relationships and are evaluated in the moment and over time. Expectancy violations theory (EVT) explains how people interpret and respond to behavior that violates culturally normative or relationally patterned expectations (Burgoon, 1993). People have expectancies for any given communication situation, but the salience and importance of expectancies are based on actor, relationship, and context variables (Burgoon, 1993). For instance, when people's behavior does not fit the expectancy for other communicators, then those behaviors may emotionally and physiologically arouse or distract their partner. As a result, receivers evaluate the violation valence on a continuum of positive-to-negative based on perception of the violators (i.e., reward value), relational history, and the violation context (Burgoon, 1993). Traditionally, "a violation ultimately has a valence attached to it that defines the violation as positive or negative" (Burgoon, 1993, p. 37). However, minimal research has explored how relational experiences can contain multiple violations that get evaluated as positive, negative, or even change over time.

For instance, consider a surprise birthday party - as a positively and negatively valenced violation of relational expectations. The behaviors used to plan the RSEs could be evaluated as a negative expectancy violation because the giver was deceptive, but the event itself might be a positive expectancy violation. Then the outcomes carry relational maintenance implications that could be associated with dynamic evaluations of the RSE over time as the expectations for birthdays in that relationship evolve. It is likely that individual differences (e.g., 
comfort with surprises), features of the event (e.g., degree of importance), and characteristics of the partner (e.g., desire to maintain relationship into the future) all factor into how individuals arrive at emotional responses and perceived relational outcomes for RSEs. These layers of complexity are demonstrated by numerous participants reporting both positively and negatively valanced outcomes. The paradox arose when people perceived the RSE as an unexpected positive outcome ("We became closer") yet also perceived a negative outcome in the process ("It complicated our overall relationship and many questions were left unanswered"). These simultaneous positive and negative valences of expectancy violations work to expand EVT theorizing to a more complex evaluation process that can have competing evaluations and change over time. Furthermore, cultural norms, relational history, and context add complexity to understanding the evaluations and relational benefits and drawbacks of RSEs. The phenomenon of RSEs offers an opportunity to explore how deceptive and relationally enhancing maintenance behaviors complicate relational expectations.

The second theoretical connection to consider as a result of the findings of this study pertains to conceptualizing relational maintenance behaviors as either positive (i.e., prosocial) or negative (i.e., antisocial). RSEs present a potential paradox for conceptualizing relational maintenance because they employ deceptive behaviors (negative maintenance), regardless if perceived that way by relational partners, for benevolent outcomes (positive maintenance). People can use deceptive messages to avoid trivial conflicts, smooth tense interactions, or show affection that ultimately works to maintain a relationship, even if the intention was not present (Cole, 2001; Guthrie \& Kunkel, 2013). But often, use of deception in relationships is considered antisocial. Kalbfleisch (2001) found that deceptive messages were negatively associated with positive relational maintenance behaviors. In this way, RSEs are enacted for prosocial relational development, but use deception (i.e., negative maintenance); hence the paradox. Multiple participants $(36.9 \%)$ perceived the process of the RSE to be deceptive and others may have experienced deceptive behaviors during the RSE, yet did not perceive them to be deceptive because the giver was benevolent or the outcomes were positive. For instance, "The information she withheld was for my happiness." Thus, typical negative maintenance forms become positive forms used for promoting novelty, which could be association with well-being.

RSEs tend to use unique forms of deception in that the deceiver conceals information to exaggerate the relational benefit as opposed to other relational deception that seeks to avoid conflict, smooth interactions, or hide actual feelings. Investigations into the use of deception in close relationships suggest relational partners are motivated to use deception to protect factual and emotional information that could harm the giver's image or relational harmony (Metts, 1989). Guthrie and Kunkel (2013) found relational partners are motivated to use deception for maintenance by "avoiding relational turbulence, eliciting positivity, evoking negative feelings, and restoring equity" (p. 147). Deception is used to intentionally conceal information and is motivated by avoidance of causing relational problems (Spitzberg \& Cupach, 2007). As such, RSEs can be thought of as a unique form of maintenance with the goal of deceiving for a time, but later revealing information to enhance a relationship rather than using deception to protect relationally damaging information from getting out.

\section{Practical Implications}

Practical implications of these findings suggest that certain types of deception can enhance relationships, if employed in the right circumstances. Although deception, including secret keeping, is often perceived as negative, this study provides evidence that strategic forms of deception used to enact RSEs can be beneficial for relationships. According to this typology, RSEs are best enacted as actions by doing something special 
for a partner rather than verbal expressions of maintenance. Both material (e.g., gifts) and experiential (e.g., trips) types of surprises manifested as acceptable and beneficial in relationships. Research demonstrates that experiential purchases, in particular, are perceived as less connected to money than material purchases and evaluated more based on their enjoyment (Mann \& Gilovich, 2016). People tend to feel more satisfied and happier with experiential purchases and they bring more happiness to others when compared to material purchases (Howell \& Hill, 2009). Our findings suggest that the novelty and excitement of surprises as enacted relational maintenance may provide freshness to a stagnant or predictable relationship, potentially leading to improved relational satisfaction, happiness, and well-being. For people interested in surprising their partner, it might be prudent to start with a low-stakes surprise (e.g., taking a partner to lunch) to get a feel for the relational expectations and rules surrounding these actions and then decide whether or not to build to more elaborately orchestrated RSEs.

\section{Limitations and Future Directions}

The sample is predominately homogeneous (college-aged, European American, and female), which limits representation from a larger population. Given that various relationship types were represented future research should consider narrowing the focus to a particular type (e.g., romantic relationships) to determine how types of RSEs might occur and function differently based on unique close relationship structures. Participants only described salient surprise experiences that were intended to be positive. Although participants articulated some relational drawbacks, a different prompt may expand possibilities for describing other types of surprises. Deception was not defined for participants. Participants most likely conceptualized deception in various ways and providing a specific definition might have yielded different results. When participants reported behavior that they perceived as altruistic for their relationship it might not have been labeled as deceptive, even though the behaviors themselves would be classified as deception as defined in this study. Future studies investigating relational surprises can build on this typology and confirm these types of surprises in other relational contexts and circumstances. Given that retrospective accounts can be infused with subsequent interpretations and feelings, experience sampling methods could prove fruitful in future research. Additionally, longitudinal studies of relational outcomes for surprise experiences could demonstrate how perceptions about RSEs change over time. When studying the enactment and outcomes of RSEs, such as relational history and cultural norms, other variables could broaden the EVT application.

Overall, future research should continue to investigate surprises, and other forms of strategic deception, such as gender reveal surprises for babies. Researchers can employ the framework of EVT by establishing expectancies for these behaviors and assessing how people form evaluations when those expectations are violated. Relationship researchers are well positioned to further explore relational implications of seemingly paradoxical or "ends-justify-the-mean" behavior intertwined within relational maintenance. With continued research understanding the nuances of relational maintenance can be wielded for promoting behaviors that lead to happy, satisfied, and fulfilling close relationships.

\section{Notes}

i) In the literature, low-stakes social lies are most often referred to as white lies. However, we avoid using this label as it is considered problematic by some scholars. These types of lies can also be demarcated further based on the benefactor of the lie. For example, there are pareto lies that are self-serving lies which benefit the speaker, and altruistic lies that benefit the receiver/listener. 
ii) To determine possible group differences between romantic and non-romantic partners, chi-square (for open-ended responses) and $t$-test (for closed-ended measures) analyses were performed and found no statistically significant differences. Thus, all relational types were analyzed together.

iii) RQ1 "Describe the surprise experience. What happened?"

$R Q 2 A$ "Describe the relational benefits, if any, occurring from the surprise experience."

RQ2B "Describe the relational drawbacks, or negatives, that are a consequence of the surprise."

RQ4 "Why was it (not) deceptive?"

iv) Krippendorf's $\alpha$ is a flexible, established measure of reliability for nominal variables and it operates as a conservative index with acceptable alphas of .60 or higher (Hayes \& Krippendorff, 2007).

v) Participants did not observe negative aspects as easily and readily as the positive aspects. Societal norms often imply that surprises are positive and accompany beneficial relationship maintenance practices, as did these findings. We attempted to elicit both negative and positive qualities. As such, we acknowledge a slight negative bias in our RQs word choices suggesting potential negative valence on the perception of surprise as deceptive.

vi) Group differences (gave vs. received) about perceptions of relational rule violations were not calculated due to insufficient sample size (only three people perceived the surprise as a rule violation).

\section{Funding}

The authors have no funding to report.

\section{Competing Interests}

The authors have declared that no competing interests exist.

\section{Acknowledgments}

The authors have no support to report.

\section{References}

Afifi, T. D., Caughlin, J., \& Afif, W. A. (2007). Exploring the dark side (and light side) of avoidance and secrets. In B. Spitzberg \& B. Cupach (Eds.), The dark side of interpersonal relationships (3rd ed., pp. 61-92). Mahwah, NJ, USA: Erlbaum.

Afifi, W. A., \& Metts, S. (1998). Characteristics and consequences of expectation violations in close relationships. Journal of Social and Personal Relationships, 15(3), 365-392. https://doi.org/10.1177/0265407598153004

Aknin, L. B., Fleerackers, A. L., \& Hamlin, J. K. (2014). Can third-party observers detect the emotional rewards of generous spending? Journal of Positive Psychology, 14(3), 198-203. https://doi.org/10.1080/17439760.2014.888578

Aron, A., \& Aron, E. N. (1996). Love and the expansion of the self: The state of the model. Personal Relationships, 3(1), 45-58. https://doi.org/10.1111/j.1475-6811.1996.tb00103.x

Baker, L. R., McNulty, J. K., Overall, N. C., Lambert, N. M., \& Fincham, F. D. (2013). How do relationship maintenance behaviors affect individual well-being? A contextual perspective. Social Psychological and Personality Science, 4(3), 282-289. https://doi.org/10.1177/1948550612452891

Biziou-van-Pol, L., Haenen, J., Novaro, A., Occhipinti Liberman, A., \& Capraro, V. (2015). Does telling white lies signal prosocial preferences? Judgment and Decision Making, 10, 538-548. https://doi.org/10.2139/ssrn.2617668 
Burgoon, J. K. (1993). Interpersonal expectations, expectancy violations, and emotional communication. Journal of Language and Social Psychology, 12(1-2), 30-48. https://doi.org/10.1177/0261927X93121003

Camden, C., Motley, M. T., \& Wilson, A. (1984). White lies in interpersonal communication: A taxonomy and preliminary investigation of social motivations. Western Journal of Speech Communication, 48(4), 309-325. https://doi.org/10.1080/10570318409374167

Canary, D. J., \& Stafford, L. (1994). Maintaining relationships through strategic and routine interaction. In D. J. Canary \& L. Stafford (Eds.), Communication and relational maintenance (pp. 6-23). New York, NY, USA: Academic Press.

Caughlin, J. P., Scott, A. M., Miller, L. E., \& Hefner, V. (2009). Putative secrets: When information is supposedly a secret. Journal of Social and Personal Relationships, 26(5), 713-743. https://doi.org/10.1177/0265407509347928

Cole, T. (2001). Lying to the one you love: The use of deception in romantic relationships. Journal of Social and Personal Relationships, 18(1), 107-129. https://doi.org/10.1177/0265407501181005

Dainton, M. (2000). Maintenance behaviors, expectations for maintenance, and satisfaction: Linking comparison levels to relational maintenance strategies. Journal of Social and Personal Relationships, 17(6), 827-842. https://doi.org/10.1177/0265407500176007

Dainton, M., \& Gross, J. (2008). The use of negative behaviors to maintain relationships. Communication Research Reports, 25(3), 179-191. https://doi.org/10.1080/08824090802237600

DePaulo, B. M., \& Kashy, D. A. (1998). Everyday lies in close and casual relationships. Journal of Personality and Social Psychology, 74(1), 63-79. https://doi.org/10.1037/0022-3514.74.1.63

Dindia, K., \& Canary, D. J. (1993). Definitions and theoretical perspectives on maintaining relationships. Journal of Social and Personal Relationships, 10(2), 163-173. https://doi.org/10.1177/026540759301000201

Dunbar, N. E., Gangi, K., Coveleski, S., Adams, A., Bernhold, Q., \& Giles, H. (2016). When is it acceptable to lie? Interpersonal and intergroup perspectives on deception. Communication Studies, 67(2), 129-146. https://doi.org/10.1080/10510974.2016.1146911

Erat, S., \& Gneezy, U. (2012). White lies. Management Science, 58(4), 723-733. https://doi.org/10.1287/mnsc.1110.1449

Gillen, H. G., \& Horan, S. M. (2013). Toward an understanding of the relationships among deceptive affection, deceptive beliefs, and relational qualities. Communication Research Reports, 30(4), 352-358.

https://doi.org/10.1080/08824096.2013.836629

Gordon, A. K., \& Miller, A. G. (2000). Perspective differences in the construal of lies: Is deception in the eye of the beholder? Personality and Social Psychology Bulletin, 26(1), 46-55. https://doi.org/10.1177/0146167200261005

Guthrie, J., \& Kunkel, A. (2013). Tell me sweet (and not-so-sweet) little lies: Deception in romantic relationships. Communication Studies, 64(2), 141-157. https://doi.org/10.1080/10510974.2012.755637

Hart, C. L., Curtis, D. A., Williams, N. M., Hathaway, M. D., \& Griffith, J. D. (2014). Do as I say, not as I do: Benevolent deception in romantic relationships. Journal of Relationships Research, 5(e8), ), 1-6. https://doi.org/10.1017/jrr.2014.8

Hayes, A. F., \& Krippendorf, K. (2007). Answering the call for a standard reliability measure for coding data. Communication Methods and Measures, 1(1), 77-89. https://doi.org/10.1080/19312450709336664 
Heish, H.-F., \& Shannon, S. E. (2005). Three approaches to qualitative content analysis. Qualitative Health Research, 15(9), 1277-1288. https://doi.org/10.1177/1049732305276687

Horan, S. M., \& Booth-Butterfield, M. (2011). Is it worth lying for? Physiological and emotional implications of recalling deceptive affection. Human Communication Research, 37(1), 78-106. https://doi.org/10.1111/j.1468-2958.2010.01394.x

Horan, S. M., \& Booth-Butterfield, M. (2013). Understanding the routine expression of deceptive affection in romantic relationships. Communication Quarterly, 61(2), 195-216. https://doi.org/10.1080/01463373.2012.751435

Howell, R. T., \& Hill, G. (2009). The mediators of experiential purchases: Determining the impact of psychological needs satisfaction and social comparison. The Journal of Positive Psychology, 4(6), 511-522.

https://doi.org/10.1080/17439760903270993

Kalbfleisch, P. J. (2001). Deceptive message intent and relational quality. Journal of Language and Social Psychology, 20(1-2), 214-230. https://doi.org/10.1177/0261927X01020001010

Kaplar, M. E., \& Gordon, A. K. (2004). The enigma of altruistic lying: Perspective differences in what motivates and justifies lie telling within romantic relationships. Personal Relationships, 11(4), 489-507.

https://doi.org/10.1111/j.1475-6811.2004.00094.x

Krippendorff, K. (2012). Content analysis: An introduction to its methodology (3rd ed.). Thousand Oaks, CA, USA: Sage.

Levine, T. R. (2014). Truth-default theory (TDT): A theory of human deception and deception detection. Journal of Language and Social Psychology, 33(4), 378-392. https://doi.org/10.1177/0261927X14535916

Malouff, J. M., Mundy, S. A., Galea, T. R., \& Bothma, V. N. (2015). Preliminary findings supporting a new model of how couples maintain excitement in romantic relationships. American Journal of Family Therapy, 43(3), 227-237.

https://doi.org/10.1080/01926187.2015.1034634

Mann, T. C., \& Gilvoch, T. (2016). The asymmetric connection between money and material vs. experiential purchases. Journal of Positive Psychology, 11(6), 647-658. https://doi.org/10.1080/17439760.2016.1152594

McCornack, S. A., \& Levine, T. R. (1990). When lies are uncovered: Emotional and relational outcomes of discovered deception. Communications Monographs, 57(2), 119-138. https://doi.org/10.1080/03637759009376190

Metts, S. (1989). An exploratory investigation of deception in close relationships. Journal of Social and Personal Relationships, 6(2), 159-169. https://doi.org/10.1177/026540758900600202

Metts, S., \& Cupach, W. R. (2007). Responses to relational transgressions: Hurt, anger, and sometimes forgiveness. In W. R. Cupach, \& B. H. Spitzberg (Eds.) The dark side of interpersonal communication (pp. 243-274). Mahwah, NJ, USA: Lawrence Erlbaum Associates.

Mills, C. B., \& Babrow, A. S. (2003). Teasing as a means of social influence. Southern Journal of Communication, 68(4), 273-286. https://doi.org/10.1080/10417940309373267

Ortony, A., Clore, G. L., \& Collins, A. (1988). The cognitive structure of emotions. New York, NY, USA: Cambridge Press.

Redlick, M. H., \& Vangelisti, A. L. (2018). Affection, deception, and evolution: Deceptive affectionate messages as mate retention behaviors. Evolutionary Psychology, 16(1), 1-11. https://doi.org/10.1177/1474704917753857 
Reisenzein, R. (2000). The subjective experience of surprise. In H. Bless \& J. P. Forgas (Eds.), The message withln: The role of subjective experience in social cognition and behavior (pp. 262-279). Philadelphia, PA, USA: Psychology Press.

Roggensack, K. E., \& Sillars, A. (2014). Agreement and understanding about honesty and deception rules in romantic relationships. Journal of Social and Personal Relationships, 31(2), 178-199. https://doi.org/10.1177/0265407513489914

Spitzberg, B. H., \& Cupach, W. R. (2007). The dark side of interpersonal communication. Mahwah, NJ, USA: Erlbaum.

Stafford, L. (2003). Maintaining romantic relationships: A summary and analysis of one research program. In D. J. Canary \& M. Dainton (Eds.), Maintaining relationships through communication (pp. 51-77). Mahwah, NJ, USA: Lawrence Erlbaum Associates.

Stafford, L., \& Canary, D. J. (1991). Maintenance strategies and romantic relationship type, gender and relational characteristics. Journal of Social and Personal Relationships, 8(2), 217-242. https://doi.org/10.1177/0265407591082004

Stets, J. E., \& Turner, J. H. (2008). The sociology of emotions. In M. Lewis, J. M. Haviland-Jones, \& L. F. Barrett (Eds.) Handbook of emotions (3rd ed., pp. 33-46). New York, NY, USA: Guilford Press.

Vangelisti, A. L., \& Young, S. L. (2000). When words hurt: The effect of perceived intentionality on interpersonal relationships. Journal of Social and Personal Relationships, 17(3), 393-424. https://doi.org/10.1177/0265407500173005 